\title{
Postural control in 13-year-old soccer players
}

\author{
Ewa Bieć • Michał Kuczyński
}

Accepted: 14 June 2010/Published online: 26 June 2010

(C) The Author(s) 2010. This article is published with open access at Springerlink.com

\begin{abstract}
To evaluate the effect of early systematic soccer training on postural control we measured centerof-pressure (COP) variability, range, mean velocity and frequency in bipedal quiet stance with eyes open (EO) and closed (EC) in 44 boys aged 13 (25 boys who practiced soccer for 5-6 years and 19 healthy boys who did not practice sports). The soccer players had better stability, particularly in the medial-lateral plane $(\mathrm{M} / \mathrm{L})$; their COP variability and range were lower than in controls in both EO $(p<0.05)$ and EC $(p<0.0005)$ condition indicating that the athletes were less dependent on vision than nonathletes. Improved stability of athletes was accompanied by a decrease in COP frequency $(p<0.001$ in EO, and $p<0.04$ in EC) which accounted for lower regulatory activity of balance system in soccer players. The athletes had lower COP mean velocity than controls $(p<0.0001$ in both visual condition), with larger difference in the $\mathrm{M} / \mathrm{L}$ than A/P plane ( $p<0.00001$ and $p<0.05$, respectively). Postural behavior was more variable within the non-athletes than soccer players, mainly in the EC stances ( $p<0.005$ for all COP parameters). We conclude that: (1) soccer training described was efficient in improving the $\mathrm{M} / \mathrm{L}$ postural control in young boys; (2) athletes developed specific postural strategies characterized by decreased COP frequency and lower reliance on vision.
\end{abstract}

Communicated by Jean-René Lacour.

E. Bieć · M. Kuczyński ( $\square)$

Academy of Physical Education, Wrocław, Poland

e-mail: michal.kuczynski@awf.wroc.pl

M. Kuczyński

University of Technology, Opole, Poland
Keywords Postural sway $\cdot$ Stability $\cdot$ Soccer . Adolescent

\section{Introduction}

Investigation of postural stability in sports which require excellent postural performance provides insight into development of specific postural strategies (Perrin et al. 2002; Vuillerme et al 2004; Paillard et al. 2006). Several years of training and participation in demanding competition may significantly modify the redundancy of postural control system and lead to the discipline-oriented (Davlin 2004) optimal use of sensorimotor modalities responsible for body balance (Rose 1997). Understanding of these transformations is valuable in sports sciences because postural stability is an important determinant of both sports level (Era et al. 1996; Vuillerme et al. 2001; Noé and Paillard 2005), and susceptibility to injuries (McGuine and Keene 2006). It may be also inspiring for clinicians interested in designing new rehabilitation therapies.

Superior postural stability in athletes has been reported in several individual sports disciplines (Era et al. 1996; Golomer et al. 1999; Bringoux et al. 2000; Perrin et al. 2002; Noé and Paillard 2005) but only few studies focussed on popular team sports, mainly on soccer. It has been documented that soccer players have better postural stability (Bressel et al. 2007; Matsuda et al. 2008), rely less on vision (Paillard et al. 2006) and develop different postural strategies (Paillard et al. 2006) than untrained subjects. These findings indicated that some components of soccer training are favorable to postural control, however, they addressed experienced adult athletes only while little is known on the intermediate phases of the postural control development, i.e., the rate of stability improvement in 
preadolescent soccer players caused by the consecutive years of soccer training. This knowledge seems crucial in sports by providing a baseline for comparison and in rehabilitation by indicating how much specific effort is required to significantly improve postural control. Ideally, to obtain this information, a prospective study of soccer novices is necessary.

Several authors, on the other hand attempted to assess differences in postural control between athletes and normal participants (Perrin et al. 2002; Chapman et al. 2008), athletes of different level of sports expertise (Noé and Paillard 2005; Paillard et al. 2006; Chapman et al. 2008), and athletes from different sports (Vuillerme et al. 2001; Perrin et al. 2002; Vuillerme and Nougier 2004; Bressel et al. 2007; Matsuda et al. 2008) using only cross-sectional studies. These studies produced varying results from large to no differences between investigated groups and some authors admitted that these results may have been due to the different postural control in subjects at the time of their recruitment to respective sports. However, the soccer players were consistently better than other athletes (Bressel et al. 2007; Matsuda et al. 2008) and their level of competition had positive relationship with postural stability (Paillard et al. 2006; Paillard and Noé 2006). More interestingly, the expert soccer players developed the ability to shift the sensorimotor dominance from vision to proprioception (Paillard and Noé 2006) and built up a better internal representation of erect posture (Paillard et al. 2007). It has been argued that these specific postural adaptations or strategies of soccer players resulted from their experience in changing environment where vision is mainly used to collaborate with partner, to anticipate pass destination, and fixate on peripheral aspects of the match, such as the positions and movements of other players (Williams et al. 1994; Paillard and Noé 2006; Paillard et al. 2006). Thus, differences between postural strategies in athletes and non-athletes seem to have potential in elucidating the effect of soccer training on postural control regardless of their initial postural abilities.

The purpose of this study was to compare postural stability in young soccer players with their normally active counterparts (non-athletes). We hypothesized that the athletes would show: (1) better postural performance with (2) lower intragroup variances and (3) different postural strategies than the non-athletes.

\section{Methods}

Forty-four boys aged 13 ( 25 boys who practiced soccer for 5-6 years and 19 non-athletes) participated. The soccer players with a mean height of $166.5 \pm 7.5 \mathrm{~cm}$, and a mean body weight of $52.5 \pm 11.6 \mathrm{~kg}$ have trained for 5-6 years,
$2 \mathrm{~h}$ twice a week between 7 and 9 years of age and $2 \mathrm{~h}$ three times a week from the age of 10 . In order to at least partially control the selection bias, only those soccer players were included who reported no involvement into other regular sports activities before their recruitment to the soccer team. The non-athletes were healthy boys with a mean height of $168.5 \pm 5.4 \mathrm{~cm}$, and a mean body weight of $57.0 \pm 8.4 \mathrm{~kg}$ who attended physical education classes (45 min twice a week) and were not involved in any other regular physical activities. These classes followed a typical format: warm-up, skill teaching/practices, minor games, and warm down. The study was approved by the local bioethics committee and all subjects provided informed consent signed by their parents. Postural stability was assessed during two $20 \mathrm{~s}$ quiet stance trials, first with eyes open (EO) and then, after a 1 min break, with eyes closed (EC) on an AMTI (Accusway) force plate. The subjects were instructed to stand barefoot, with the hands at their sides and their feet parallel and $10 \mathrm{~cm}$ apart. A practice run was allowed prior to the test to ensure that the subjects felt comfortable in the laboratory area. The sampling rate was $20 \mathrm{~Hz}$ and sampling time $20 \mathrm{~s}$ resulting in 400 sampling segments in each recorded center-of-pressure (COP) time series in both the anterior/posterior $(\mathrm{A} / \mathrm{P})$ and medial/lateral $(\mathrm{M} / \mathrm{L})$ planes. Each recording started $10 \mathrm{~s}$ after the subject was ready for testing to eliminate possible transients in the COP data.

The dependent variables were sway variability (COP standard deviation), range, mean velocity $(\mathrm{MV}=$ the total COP path length divided by the sampling time), and frequency. Sway variability and velocity are commonly used to assess postural performance and lower values of these parameters indicate lesser postural stability. For the estimation of postural frequency we used a measure (Hufschmidt et al. 1980) based on the ratio of sway mean velocity and variability: Frequency $=$ MV/(Variability $\times$ $2 \pi)$. Sway frequency indexes the rate of exploratory actions of the equilibrium system accounting for the amount of activity required to maintain stability (Olivier et al. 2008). It is a rough measure of the number of COP turnings (for-aft and left-right) per second. When postural task is more challenging or a specific group of subjects is less trained, the COP frequency increases (Carpenter et al. 1999; Kuczyński 1999; Dault et al. 2003; Meyer et al. 2004).

The data were tested for normal distribution and homogeneity of variances. All dependent variables were subjected to the Within (2 Visual conditions $\times 2$ Planes) $\times$ Between (2 Groups) ANOVA (Statistica 8.0) to evaluate hypothesized main effects and possible interactions. Comparison of postural performance and strategies between both the groups was performed by contrast analysis. The level of significance was set at $p=0.05$. 
Table 1 Mean (SD) of the postural stability parameters in the soccer players and controls in both planes and both visual conditions

\begin{tabular}{|c|c|c|c|c|c|c|}
\hline & \multicolumn{3}{|l|}{ Eyes open } & \multicolumn{3}{|l|}{ Eyes closed } \\
\hline & Athletes & Controls & $p$ & Athletes & Controls & $p$ \\
\hline \multicolumn{7}{|l|}{ Medial/lateral plane } \\
\hline Variability (mm) & $3.0(1.4)$ & $4.1(2.2)$ & 0.04 & $2.5(0.9)$ & $4.1(1.8)$ & 0.0003 \\
\hline Range (mm) & $15.6(10.2)$ & $22.8(17.0)$ & 0.05 & $12.7(4.8)$ & $21.9(10.3)$ & 0.0003 \\
\hline Mean velocity $(\mathrm{mm} / \mathrm{s})$ & $6.1(2.9)$ & $10.5(3.2)$ & 0.0001 & $5.7(1.9)$ & $10.9(4.7)$ & 0.0001 \\
\hline Frequency $(\mathrm{Hz})$ & $0.33(0.07)$ & $0.47(0.10)$ & 0.001 & $0.37(0.11)$ & $0.44(0.12)$ & 0.04 \\
\hline \multicolumn{7}{|l|}{ Anterior/posterior plane } \\
\hline Variability (mm) & $3.2(1.1)$ & $3.9(1.5)$ & 0.07 & $3.4(1.4)$ & $4.0(1.3)$ & $\mathrm{n} / \mathrm{s}$ \\
\hline Range (mm) & $15.6(7.2)$ & $18.5(6.3)$ & $\mathrm{n} / \mathrm{s}$ & $16.1(5.6)$ & $20.5(6.9)$ & 0.02 \\
\hline Mean velocity $(\mathrm{mm} / \mathrm{s})$ & $6.6(2.9)$ & $8.0(2.5)$ & 0.04 & $7.5(2.1)$ & $9.4(3.3)$ & 0.03 \\
\hline Frequency $(\mathrm{Hz})$ & $0.34(0.09)$ & $0.36(0.12)$ & $\mathrm{n} / \mathrm{s}$ & $0.39(0.14)$ & $0.39(0.14)$ & $\mathrm{n} / \mathrm{s}$ \\
\hline
\end{tabular}

The $p$ values are significance levels of the between-group differences resulting from planned comparisons

$n / s$ non-significant

\section{Results}

Both investigated groups were similar as regards their anthropometric data. Neither the body mass $(p>0.16)$ nor the body height $(p>0.34)$ differentiated between the soccer players and non-athletes.

The traditional measures of the COP dispersion displayed main effects of Group: $F(1,42)=10.85 ; p=0.002$ and $F(1,42)=11.54 ; p=0.0015$ for the COP variability and range, respectively. The variability was $33 \%$ and range $40 \%$ larger in non-athletes than in soccer players. In addition, there was a Vision $\times$ Plane interaction $[F(1,42)=4.54$; $p=0.038$ ] for range only which arose because eyes closure differently affected the latter parameter: the range decreased in the $\mathrm{M} / \mathrm{L}$ and increased in the $\mathrm{A} / \mathrm{P}$ plane. It was only the soccer players who contributed to the decreased range with EC displaying a similar withingroup Vision $\times$ Plane interaction $[F(1,24)=5.07 ; \quad p=0.034]$. The non-athletes showed slight increase in the COP range in both the planes as a result of eyes closure.

The COP MV displayed main effect of Group $[F(1,42)=23.42 ; p=0.00002]$ indicating a $50 \%$ larger values in non-athletes than in soccer players. There was also a Group $\times$ Plane interaction $[F(1,42)=23.61$; $p=0.00002$ ] which accounted for larger differences between these groups in the M/L (80\%) than in the $\mathrm{A} / \mathrm{P}$ $(23 \%)$ plane. A Vision $\times$ Plane interaction for the COP MV $[F(1,42)=17.87 ; p=0.0002]$ showed that eyes closure had destabilizing effect on posture in the AP plane only.

The results of ANOVA on the COP frequency showed a main effect of Group $[F(1,42)=4.99 ; p<0.03]$ and Plane $[F(1,42)=12.42 ; p=0.001]$ indicating lower rate of postural corrections in soccer players. A Group $\times$ Plane interaction $[F(1,42)=7.70 ; p<0.008]$, like in the case of
COP MV, accounted for larger differences between these groups in the M/L (30\%) than in the A/P (4\%) planes.

Beside the differences between both the groups resulting from ANOVA, we found much larger variances of several $\mathrm{M} / \mathrm{L}$ posturographic parameters in the non-athletes than in soccer players. This included: range $(p=0.01$ with EO) and $\mathrm{MV}$, range and variability with EC $(p=0.00009$, $p=0.0006$, and $p=0.002$, respectively). The direct comparison of all stabilographic parameters between both the groups in the M/L or A/P planes and with the EO or closed is provided in Table 1 .

\section{Discussion}

The purpose of this study was to compare postural performance and strategies between two groups of 13-year-old boys: soccer players with training experience between 5 and 6 years, and age-matched non-athletes. Our data provided support for three hypotheses developed: (1) postural performance was significantly better in soccer players who showed particularly large advantage over non-athletes in the M/L plane; (2) the individual differences were significantly larger in non-athletes, mainly in EC trials; (3) soccer players exhibited different postural strategies than nonathletes-soccer players had lower rate of postural corrections which accounted for increased sensory threshold, more feed-forward control and higher postural automaticity than that of non-athletes.

Better postural performance of soccer players in the $\mathrm{M} / \mathrm{L}$ plane

Overall, the soccer players showed superior body balance compared with the non-athletes in terms of much lower 
COP variability, range, and MV as assessed by the main effects of Group on these two parameters. The results of soccer players are very close to those of healthy young adults (Kuczyński and Wieloch 2008; Olivier et al. 2008) indicating that our 13-year soccer players had a severalyear lead over the non-athletes and that this lead may be achieved by means of a relatively moderate training. On the other hand, the stability of our non-athletes concurs with the results recently reported in children aged 7-12 (Olivier et al. 2008) showing that the reported plateau in postural development may extend until the age of 13 . Comparing both the planes, we found larger differences in balance performance between both the groups in the $\mathrm{M} / \mathrm{L}$ plane which probably indicates that playing soccer and the specific exercises improve $\mathrm{M} / \mathrm{L}$ stability more than $\mathrm{A} / \mathrm{P}$ stability. It is also possible that postural control in children matures faster in the A/P than in the $\mathrm{M} / \mathrm{L}$ plane. This finding implies that, when a need for stability improvement is considered, priority be given to exercises which reinforce the $\mathrm{M} / \mathrm{L}$ stability. One of such exercises might be soccer training as suggested by Paillard et al. (2006) who found that the level of expertise in soccer affected the COP spectral energy distribution in the $\mathrm{M} / \mathrm{L}$ plane only and argued that soccer predominantly requires fine postural control in the M/L plane. Our results extended this argument from the soccer players at national and regional level of competition to the beginners demonstrating high effectiveness of low-intensity soccer training in improving the $\mathrm{M} / \mathrm{L}$ balance performance.

The mechanisms responsible for improvement in postural performance

Was training the sole factor that led to the improved postural stability in soccer players? One may argue that soccer candidates who were selected to this sport based on some motor performance criteria might have had better baseline postural stability than the non-athletes. However, the significance of this potentially confounding factor is arguable in view of the weak relationships between different motor abilities (Schmidt and Lee 1999) and reported plateau in postural stability between 7 and 12 years of age (Olivier et al. 2008). Still, alternative explanations of the exceptional balance performance in our young soccer players should be considered, e.g., gravitating toward specific sports (Matsuda et al. 2008; Chapman et al. 2008) and facilitated learning (Perrin et al. 2002).

Although in view of the above discussion attributing this fine control to systematic soccer-oriented physical activities seems plausible, the most relevant and pragmatic goal of this study is to identify possible neurophysiologic changes or sensorimotor modalities which might have emerged as a result of these activities. In other words, it is important to realize why soccer training improved postural stability and what does it tell us. Our data indicated that better postural control in soccer players was accompanied with significantly lower values of their sway frequency when compared to non-athletes in the ML plane. Sway frequency which indexes the rate of postural corrections is a good indicator of postural strategies development due to maturation and/or training. There are several lines of evidence to support this claim. First, very young children have been shown to use higher rate of postural corrections (Riach and Hayes 1987) which may be accounted for by the predominance of feedback responses (Haas et al. 1989). The effective feedforward postural adjustments turn up later (Haas et al. 1989) and partially replace this reactive strategy which results in a decrease of the COP frequency. Due to the specific training, which requires hundreds of alternating short activities constantly challenging balance in every training session, the soccer players may have acquired this ability much earlier than the controls. Second, experience in dynamic standing tasks improves postural stability by increasing the safety margins (Patton et al. 2000). Increased safety margins open the way to higher sensory thresholds allowing for smoother sway excursions that should result in slowing down the rate of postural corrections. Third, learning of new postural activity leads to better performance which usually results from an increased automaticity level. Increased automaticity is associated with higher robustness of postural system to shifts of attention and with the overall lower demand for attentional resources (Logan 1988; Milton et al. 2004). Thus, the decreased COP frequency in soccer players may be accounted for by eliminating some "noise" (Olivier et al. 2008) which was introduced by redundant motor units involved in postural regulation at the early stage of motor learning. The specific training of our soccer players seemed to benefit from some of these processes leading to higher sensory thresholds, more feedforward control, decreased dependence on attention and increased level of automaticity. Overall, this resulted in significant improvement of postural performance with additional benefit of lesser engagement of central control.

\section{Withingroup variability of the COP measures}

Our results revealed significant differences between both the groups regarding their withingroup variability of all COP measures. The much less variability in the soccer players may have reflected a ceiling effect in that the 13-year-olds have reached some optimal level of postural control or that their training has lost its ability to improve further balance. An alternative explanation is that these soccer players who had the worst balance at the time they started the soccer career benefited most from training. 
Regardless the practical implications, each of the latter explanations is speculative and requires a follow-up study. The large variability in the non-athletes was not surprising due to the different rate of postural maturation (Riach and Hayes 1987; Nolan et al. 2005). However, these large individual differences in postural stability in children and adolescents may confound the researchers in drawing conclusions from stabilographic studies. For instance, Peterson et al. (2006) after investigating 154 children aged 6-12 concluded that age alone accounted for only $16 \%$ of the total postural stability variance, with height, weight, BMI and gender adding another $4 \%$ contribution. The latter authors asked a question: what factors comprise the remaining $80 \%$ ? Searching for an answer to this question is one of the fundamental goals of researchers specializing in child development. We believe that our study provides indirect evidence that a fair part of these $80 \%$ comes from physical activity.

In view of the results of this study, which showed that systematic soccer training of low intensity improved postural performance and strategies, and decreased intra-subject differences in all stability parameters, we are tempted to propose that such training was the main agent contributing to accelerated maturation of postural control system in our young soccer players. Indeed, if training was not responsible for the substantial improvement in postural control, then the 13-year-old soccer players should have even larger intra-subject differences than non-athletes because the former group would include some players with outstanding postural abilities. It is possible that there are several other factors related to physical activity (e.g., its type, intensity, frequency, and timing) which may significantly modify and optimize the postural control system in young persons long before their biological maturation. Thus, further investigation of specific relationships between these factors and development of postural stability in children is warranted as it may open new perspectives in physiotherapy and in sports requiring special balance abilities.

Open Access This article is distributed under the terms of the Creative Commons Attribution Noncommercial License which permits any noncommercial use, distribution, and reproduction in any medium, provided the original author(s) and source are credited.

\section{References}

Bressel E, Yonker JC, Kras J, Heath EM (2007) Comparison of static and dynamic balance in female collegiate soccer, basketball, and gymnastics athletes. J Athl Train 42:42-46

Bringoux L, Marin V, Nougier V, Barraud PA, Raphel C (2000) Effects of gymnastics expertise on the perception of body orientation in the pitch dimension. J Vestib Res 10:251-258
Carpenter MG, Frank JS, Silcher CP (1999) Surface height effects on postural control: a hypothesis for a stiffness strategy for stance. J Vestib Res 9:277-286

Chapman DW, Needham KJ, Allison GT, Lay B, Edwards DJ (2008) Effects of experience in dynamic environment on postural control. Br J Sports Med 42:16-21

Dault MC, Yardley L, Frank JS (2003) Does articulation contribute to modifications of postural control during dual-task paradigms? Cogn Brain Res 16(3):434-440

Davlin CD (2004) Dynamic balance in high level athletes. Percept Mot Skills 98:1171-1176

Era P, Konttinen N, Mehto P, Saarelas P, Lyytinen H (1996) Postural stability and skilled performance - a study on top level and naive rifle shooters. J Biomech 29:301-306

Golomer E, Cremieux J, Dupui P, Isableu B, Ohlmann T (1999) Visual contribution to self-induced body sway frequencies and visual perception of male professional dancers. Neurosci Lett 267:189-192

Haas G, Diener HC, Rapp H, Dichgans J (1989) Development of feedback and feedforward control of upright stance. Dev Med Child Neurol 31(4):481-488

Hufschmidt A, Dichgans J, Mauritz KH, Hufschmidt M (1980) Some methods and parameters of body sway quantification and their neurological applications. Arch Psychiatr Nervenkr 228:135-150

Kuczyński M (1999) The second order autoregressive model in the evaluation of postural stability. Gait Posture 9:50-56

Kuczyński M, Wieloch M (2008) Effects of accelerated breathing on postural stability. Hum Mov 9:107-110

Logan GD (1988) Automaticity, resources, and memory: theoretical controversies and practical implications. Hum Factors 30(5):583-598

Matsuda S, Demura S, Uchiyama M (2008) Centre of pressure sway characteristics during static one-legged stance of athletes from different sports. J Sports Sci 26:775-779

McGuine TA, Keene JS (2006) The effect of balance training program on the risk of ankle sprains in high school athletes. Am J Sports Med 34:1103-1111

Meyer PF, Oddsson LIE, De Luca CJ (2004) The role of plantar cutaneous sensation in unperturbed stance. Exp Brain Res 156:505-512

Milton JG, Small SS, Solodkin A (2004) On the road to automatic: dynamics aspects in the development of expertise. J Clin Neurophysiol 21:134-143

Noé F, Paillard T (2005) Is postural control affected by expertise in alpine skiing? Br J Sports Med 39:835-837

Nolan L, Grigorenko A, Thorstensson A (2005) Balance control: sex and age differences in 9- to 16-year-olds. Dev Med Child Neurol 47:449-454

Olivier I, Palluel E, Nougier V (2008) Effects of attentional focus on postural sway in children and adults. Exp Brain Res 185:341345

Paillard T, Bizid Dupui (2007) Do sensorial manipulations affect subjects differently depending on their postural abilities? $\mathrm{Br} \mathrm{J}$ Sports Med 41:435-438

Paillard T, Noé F (2006) Effect of expertise and visual contribution on postural control in soccer. Scand J Med Sci Sports 16:345-348

Paillard T, Noé F, Rivière T, Marion V, Montoya R, Dupui P (2006) Postural performance and strategy in the unipedal stance of soccer players at different levels of competition. J Athl Train 41:172-176

Patton JL, Lee WA, Pai YC (2000) Relative stability improves with experience in a dynamic standing task. Exp Brain Res 135(1):117-126

Perrin P, Deviterne D, Hugel F, Perrot C (2002) Judo, better than dance, develops sensorimotor adaptabilities involved in balance control. Gait Posture 15:187-194 
Peterson ML, Christou E, Rosengren KS (2006) Children achieve adult-like sensory integration during stance at 12-years-old. Gait Posture 23:455-463

Riach CL, Hayes KC (1987) Maturation of postural sway in young children. Dev Med Child Neurol 29:650-658

Rose DJ (1997) Motor control and learning. Allyn \& Bacon, Boston

Schmidt RA, Lee TD (1999) Motor control and learning. Human Kinetics, Champaign

Vuillerme N, Nougier V (2004) Attentional demand for regulating postural sway: the effect of expertise in gymnastics. Brain Res Bull 63:161-165
Vuillerme N, Teasdale N, Nougier V (2001) The effect of expertise in gymnastics on proprioceptive sensory integration in human subjects. Neurosci Lett 311:73-76

Williams AM, Davids K, Burwitz L, Williams JG (1994) Visual search strategies in experienced and inexperienced soccer players. Res Q Exerc Sport 65(2):127-235 